\title{
Vegetação arbórea do Faxinal Sete Saltos de Baixo, Ponta Grossa, PR ${ }^{1}$
}

\author{
Arboreal vegetation in Faxinal Sete Saltos de Baixo, \\ Ponta Grossa (Paraná, Brazil)
}

\section{Vegetación arbórea de Faxinal Sete Saltos de Baixo, Ponta Grossa (Paraná, Brasil)}

\author{
Rosemeri Segecin Moro \\ moro.uepg@gmail.com \\ Universidade Estadual de Ponta Grossa \\ Christiane Niedzielski de Lima \\ chrisnied@uol.com.br \\ Universidade Estadual de Ponta Grossa
}

\begin{abstract}
Resumo: Nos faxinais paranaenses, encontram-se remanescentes representativos da floresta com araucária manejada no Estado do Paraná. O inventário da vegetação do criadouro comunitário do Faxinal Sete Saltos de Baixo, Ponta Grossa, PR, apontou uma floresta impactada $\left(\mathrm{H}^{\prime}=2,92\right.$ e $\left.\mathrm{J}=0,78\right)$, enquadrada na tipologia de Floresta Antropizada por Sistemas Agrosilvopastoris. Foram levantados 170 indivíduos de 32 espécies e 23 gêneros de 16 famílias. A maior riqueza ocorreu em Myrtaceae, Lauraceae e Salicaceae. As espécies mais frequentes foram Eugenia pluriflora, Myrcia hatschbachii e Cinnamodendron dinisii. As espécies de maior IVI foram Eugenia pluriflora, Cinnamodendron dinisii, Myrcia hatschbachii e Casearia inaequilatera.
\end{abstract}

Palavras-chave: Sistema Faxinal. Levantamento fitossociológico. Floresta Ombrófila Mista.

\begin{abstract}
The faxinal system concentrates significant part of managed Araucaria forest remnants of the Paraná State, southern Brazil. The inventory of the communitarian grazing ground vegetation of the Faxinal Sete Saltos de Baixo, at Ponta Grossa, PR, pointed to an impacted forest $\left(\mathrm{H}^{\prime}=2.92 ; \mathrm{J}=0.78\right)$ framed typologically as anthropized forest by agroforestry systems. We observed 170 individuals of 32 species and 23 genera from 16 families. The biggest richness occurred in Myrtaceae, Lauraceae, and Salicaceae. The most frequent species were Eugenia pluriflora, Myrcia hatschbachii, and Cinnamodendron dinisii. The species of greater IVI were Eugenia pluriflora, Cinnamodendron dinisii, Myrcia hatschbachii, and Casearia inaequilatera.
\end{abstract}

Keywords: Faxinal system. Phytosociology. Mixed Ombrophilous Forest.

1 Este trabalho se inseriu no projeto "O Sistema Faxinal e sua sustentabilidade enquanto forma de organização camponesa na região da Mata de Araucária do Paraná", financiado pela Fundação Araucária. 
Resumen: En los faxinais de Paraná se encuentran remanentes representativos del bosque de araucaria manejado en el Estado de Paraná. El inventario de la vegetación del creador de la Comunidad del Faxinal Sete Saltos, Ponta Grossa, PR mostraron un bosque impactado $\left(\mathrm{H}^{\prime}=2.92\right.$ y J = 0,78), encuadrado en la tipología del bosque antropizado por los sistemas de Agrosilvopastoris. Se levantó 170 individuos de 32 especies y 23 géneros de 16 familias. La mayor riqueza ocurrió en Myrtaceae, Lauraceae y salicaceae. Las especies más frecuentes fueron Eugenia Pluriflora, y Myrcia hatschbachii, Cinnamodendron dinisii. Las especies con mayor IVI fueron Eugenia pluriflora, Cinnamodendron dinisii, Myrcia hatschbachii y Casearia inaequilatera.

Palabras claves: Sistema Faxinal. Levantamiento Fitosociológico. Bosque. Ombrófila Mista.

\section{INTRODUÇÃO}

O Estado do Paraná possui uma expressiva atividade agrícola, com grande relevância em termos histórico, social e de produção econômica. Entre os sistemas de produção tradicionais, o Sistema Faxinal é pouco conhecido pela comunidade científica e pouco valorizado pela sociedade em geral, mesmo já tendo abrangido um quinto do território paranaense (SAHR; CUNHA, 2005), em áreas onde se encontravam as Florestas com araucária.

Entende-se por Sistema Faxinal o sistema de produção camponês tradicional, característico da região Centro-Sul do Paraná que tem como traço marcante o uso coletivo da terra para produção animal (PARANÁ, 1997). Segundo Chang (1988), o Sistema Faxinal segrega as Terras de Plantar localizadas geralmente nas encostas, em áreas mais íngremes, das terras do Criadouro Comunitário, em vales com relevo suavemente ondulado e presença de cursos d'água, que abrigam um ambiente florestal alterado pelo pastoreio extensivo.

No Faxinal, ocorria a presença das espécies florestais como o pinheiro (Araucaria angustifolia (Bertol.) Kuntze) e a erva-mate (Ilex paraguariensis A.-St.Hil.), além de apresentar razoáveis condições de pastagens naturais. O Faxinal era mantido para práticas extrativistas de madeira e erva-mate, além de servir de espaço para a criação extensiva de animais. Neste sentido, para Gubert Filho (1987), o Sistema Faxinal é uma experiência única, de criar animais comunitariamente utilizando, para isso, áreas de vegetação nativa.

De acordo a visão de décadas passadas (SEPLAN, 1994), os criadouros seriam formados por florestas com fisionomias variadas, densas ou ralas, que constituíam remanescentes importantes da Floresta Ombrófila Mista no Estado do Paraná, incluindo espécies nativas como araucária, erva-mate, canela-imbuia, cedro, entre outras. Esses espaços verdes poderiam constituir ambientes permanentes de preservação e reprodução de flora e fauna típicas da região. Recentemente Struminski e Strachulski (2011) levantaram, no entanto, ressalvas quanto à qualidade destas florestas, em processo acelerado de perda de diversidade devido à exploração seletiva e a sérios problemas de regeneração. 
A concepção inicial do Sistema Faxinal como uma experiência de desenvolvimento sustentável norteou seu reconhecimento formal como Unidade de Conservação, por intermédio do Decreto Estadual no 3446/97, que criou a ARESUR (Áreas Especiais de Uso Regulamentado), para incluí-lo no CEUC - Cadastro Estadual de Unidades de Conservação (IAP, 1998). Assim, os municípios que possuem faxinais como ARESUR em seu território adquirem o direito de receber, pela Lei do ICMS Ecológico (Lei Complementar no 59/91), um maior percentual na distribuição dos recursos do ICMS. A permanência, porém, dos faxinais no atual quadro de capitalização da produção agropecuária requer que eles se tornem também viáveis não só do ponto de vista ecológico (SAHR; CUNHA, 2005), mas também econômico (CHANG, 1988; SANQUETTA; MATTEI, 2006). No entanto, pouco se conhece sobre a estrutura destas florestas manejadas. Para tanto, foi realizado o levantamento florístico e fitossociológico da vegetação arbórea nas áreas de criadouro comunitário do Faxinal Sete Saltos de Baixo, Ponta Grossa, PR.

\section{CARACTERIZAÇÃO DA ÁREA}

O Faxinal Sete Saltos de Baixo, situado no distrito de Itaiacoca, município de Ponta Grossa, (Figura 1), situa-se na bacia hidrográfica do rio Sete Saltos, no Primeiro Planalto Paranaense. Com área de 3.817 ha, possui uma amplitude altimétrica de 230 metros, variando entre 720 a 960 metros em relação ao nível do mar, com áreas mais elevadas na porção sul da bacia. Com relação aos solos, predominam cambissolos e solos hidromórficos gleizados.

O Faxinal Sete Saltos de Baixo ocupa 26\% da área da bacia (992 ha), sendo 102 ha representados pelo criadouro comunitário, com florestas, várzeas, edificações e estradas, e 890 ha pela área de plantar. Quanto ao uso da terra na bacia onde se insere o Faxinal, quase 58\% da área se encontra coberta por florestas (FERREIRA; CARVALHO, 2006).

A vegetação regional é composta pela Floresta com araucária, classificada pelo IBGE como sendo uma Floresta Ombrófila Mista Montana - FOMM (VELOSO et al, 1991) que ocorre de forma contínua principalmente nos três Estados do sul do Brasil, sendo que o Estado do Paraná apresenta a maior extensão dessa unidade fitoecológica (CASTELLA; BRITEZ, 2004).

Castella e Britez (2004) descrevem a Floresta com araucária como submetida a um clima temperado, cujas geadas exercem um papel seletivo na ocorrência de determinadas espécies. Além disso, as regiões podem apresentar diversas fisionomias, as quais refletem seus estágios sucessionais, em virtude não só da diversidade de geologia, solo e relevo, como dos diferentes usos passados e atuais.

Segundo Leite (1994), a FOMM está associada a dois grupos distintos de comunidades, ambos com Araucariaceae e Lauraceae. No primeiro, o pinheiro (Araucaria angustifolia) distribui-se de forma esparsa por sobre bosque contínuo, no qual 70 a $90 \%$ do dossel é composto por imbuia (Ocotea porosa (Nees) Barroso); canela-amarela (Nectandra lanceolata Nees); canela-preta (Nectandra megapotamica (Spreng) Mez); canela-fogo (Cryptocarya aschersoniana Mez); sapopema (Sloanea monosperma Vell.); guabiroba 
(Campomanesia xanthocarpa O. Berg) e erva-mate (Ilex paraguariensis). No segundo grupo, o pinheiro (Araucaria angustifolia) forma um estrato superior bastante denso sobre um dossel de 60 a 80\% de espécies como canela-lageana (Ocotea pulchella Nees et Mart. ex Nees); canela-amarela (Nectandra lanceolata Nees \& Mart); canela-guaicá (Ocotea puberula (Rich.) Nees); canela-fedida (Nectandra grandiflora Nees); miguel-pintado (Matayba elaeagnoides Radlk.); pinheiro-bravo (Podocarpus lambertii (Klotzsh ex Eichler)); pimenteira (Cinnamodendron dinisii Schwacke); guabiroba (Campomanesia xanthocarpa O. Berg) e diversas outras Myrtaceae e Aquifoliaceae.

No Estado do Paraná, a floresta com araucária distribui-se no Primeiro, Segundo e na parte leste do Terceiro Planalto, perfazendo uma área original de $100.000 \mathrm{~km}^{2}$. Para Sanquetta e Mattei (2006), seus remanescentes abrangiam em 2001 aproximadamente $25 \%$ da área do Estado, sendo cerca de $11 \%$ em estágio inicial de regeneração, $12 \% \mathrm{em}$ estágio médio, e apenas 1,3\% em estágio avançado. Para Castella e Britez (2004), três anos depois, se manteriam cerca de $22,3 \%$ do total original nos estágios iniciais e médio de sucessão, mas apenas $0,8 \%$ em estágio avançado.

Figura 1 - Localização do Faxinal Sete Saltos de Baixo, em Ponta Grossa, PR

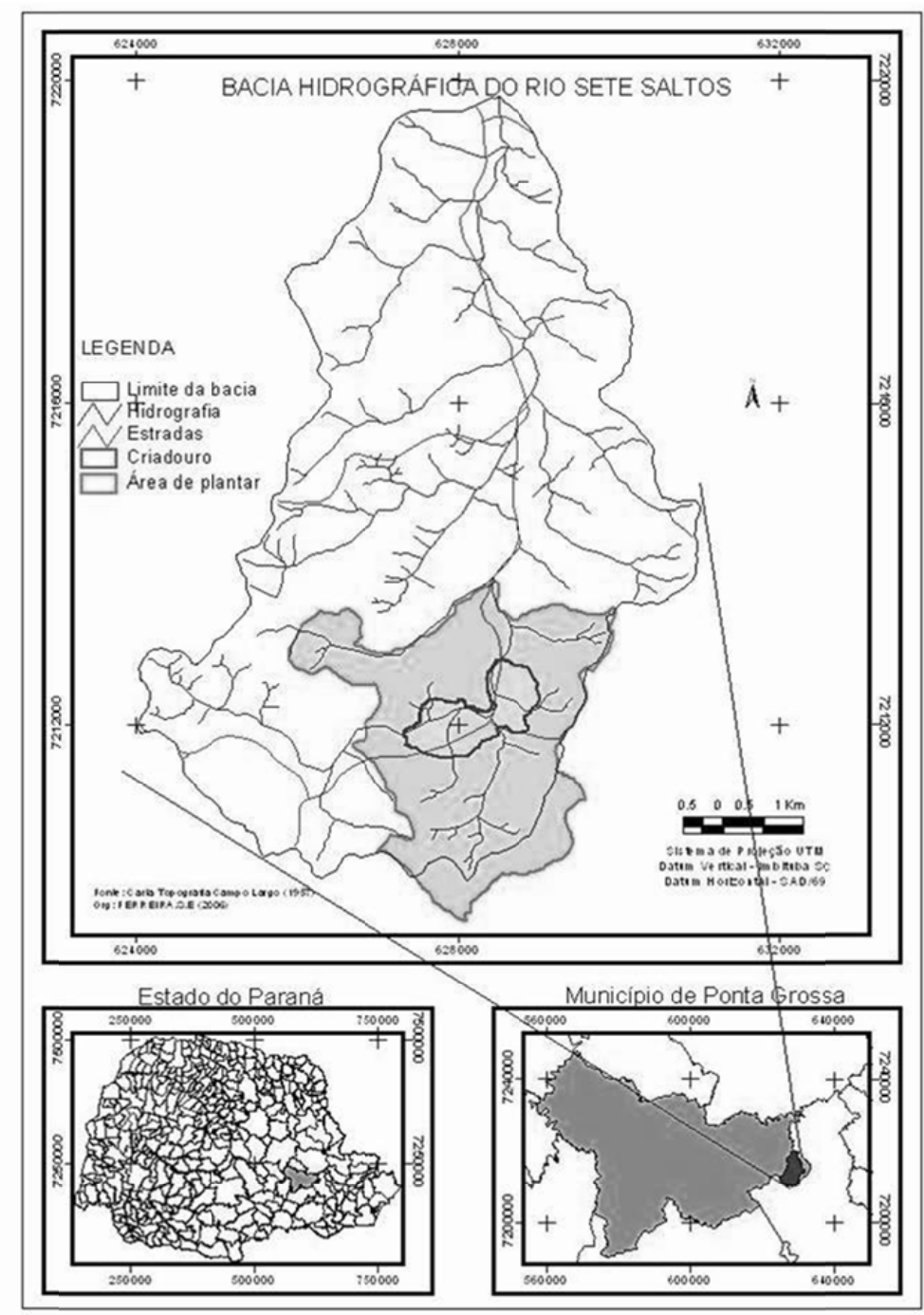

Fonte: Ferreira e Carvalho (2006) 


\section{MATERIAL E MÉTODOS}

A delimitação da área foi estruturada a partir da carta topográfica de Campo Largo (SG22-K-I, 1964), escala 1:100.000, com equidistância de 40m, além de fotografias aéreas do sobrevoo realizado no Paraná em 1980 (ITC), escala 1:25.000 e imagens do satélite CBERS II. A concepção e o manuseio da base de dados foram executados a partir da aplicação da tecnologia SIG (Sistema de Informação Geográfica), por meio de uso do software Arc View GIS®, versão 3.2.

Para o levantamento das características vegetacionais, foi realizado um levantamento florístico e fitossociológico pelo método de parcelas múltiplas no criadouro comunitário do Faxinal Sete Saltos de Baixo, ou seja, áreas acessadas por animais domésticos da comunidade faxinalense. Foram alocadas oito parcelas de $15 \times 4 \mathrm{~m}\left(120 \mathrm{~m}^{2}\right)$, nas quais foram mensurados todos os indivíduos arbóreos com PAP (perímetro do(s) tronco(s) à altura do peito, ou seja, a 1,30 m do solo) igual ou superior a $10 \mathrm{~cm}$, com determinação da altura dos indivíduos de acordo com estimativa visual. As parcelas alocadas concentravam-se sobre Cambissolos. O material vegetal coletado foi encaminhado para o herbário HUPG, da Universidade Estadual de Ponta Grossa, onde foi preparado de acordo com as técnicas de Fidalgo e Bononi (1984) e identificado com o auxílio de especialistas e comparações com material vegetal do acervo. A ordenação das famílias e gêneros foi baseado no APG III (2009) e a nomenclatura das espécies foi verificada nos arquivos on-line do Kew Botanical Garden, disponível na página <http://www.theplantlist.org>.

O levantamento da estrutura do estrato se deu em termos de composição, ocorrência e frequência de espécies. Os parâmetros estruturais foram calculados com auxílio do Programa FITOPAC (SHEPHERD, 1994), de acordo com Mueller-Dumbois e Ellenberg (1974): densidade relativa (DR); frequência relativa (FR); índices de valor de importância (IVI) e de cobertura (IVC) e índice de diversidade de Shannon $\left(\mathrm{H}^{\prime}\right)$ e uniformidade de Pielou (J).

Para a caracterização da síndrome de dispersão das sementes das espécies coletadas, utilizaram-se critérios propostos por Pijl (1982) - zoocóricas, autocóricas e anemocóricas, com pesquisa em Correa (1926/1931/1952/1969;1974/1975) e Lorenzi (1992/1998). O estágio sucessional foi estimado segundo Sanquetta e Mattei (2006) e Castela e Britez (2004), de acordo com a Resolução 002/94 do CONAMA.

\section{RESULTADOS E DISCUSSÃO}

Com base na elaboração da curva de rarefação de espécies no Faxinal Sete Saltos de Baixo, evidenciou-se a suficiência amostral em termos de composição de espécies arbóreas.

Foram inventariados 170 indivíduos, distribuídos entre 32 espécies, em 23 gêneros de 16 famílias, restando dois táxons indeterminados a qualquer nível (Tabela 1). A área basal por hectare foi de $42,12 \mathrm{~m}^{2}$. A variação de diâmetro ocorreu entre 3,18 até 50,29 cm 
$(\mathrm{m}=9,62 \pm 7,69)$. A altura variou de 1,80 a 35,0 $\mathrm{m}(\mathrm{m}=8,55 \pm 4,7)$. A variação de volume observada foi de 0,0024 a $4,48 \mathrm{~m}^{3}(\mathrm{~m}=0,16 \pm 0,52)$.

Tabela 1 - Síndrome de dispersão e estágio sucessional dos táxons presentes em áreas do criadouro comum do Faxinal Sete Saltos de Baixo, Ponta Grossa, PR

\begin{tabular}{|c|c|c|c|c|}
\hline FAMÍLIA & ESPÉCIE & NOME VULGAR & DISPERSÃO & $\begin{array}{c}\text { ESTÁGIO } \\
\text { SUCESSIONAL }\end{array}$ \\
\hline AQUIFOLIACEAE & Ilex theezans Mart. & Congonha-graúda & $\mathrm{ZOO}$ & $\mathrm{I} ; \mathrm{M} ; \mathrm{A}$ \\
\hline ANNONACEAE & $\begin{array}{c}\text { Rollinia sericea } \\
\text { (R.E.Fries) } \\
\text { R.E.Fries } \\
\end{array}$ & Pinha-da-mata & $\mathrm{ZOO}$ & $\mathrm{M} ; \mathrm{A}$ \\
\hline BIGNONIACEAE & $\begin{array}{c}\text { Jacaranda } \\
\text { macrantha Cham. }\end{array}$ & Carobinha & ANE & M \\
\hline CANELLACEAE & $\begin{array}{l}\text { Cinnamodendron } \\
\text { dinisii Schwacke }\end{array}$ & Pimenteira & $\mathrm{ZOO}$ & I;M;A \\
\hline EUPHORBIACEAE & $\begin{array}{c}\text { Sapium } \\
\text { glandulosum (L.) } \\
\text { Morong. }\end{array}$ & Leiteiro & AUT & $\mathrm{I} ; \mathrm{M} ; \mathrm{A}$ \\
\hline FABACEAE & $\begin{array}{c}\text { Lonchocarpus } \\
\text { muehlbergianus } \\
\text { Hassl. } \\
\end{array}$ & Rabo-de-bugio & AUT & $\mathrm{M} ; \mathrm{A}$ \\
\hline \multirow[t]{6}{*}{ LAURACEAE } & $\begin{array}{c}\text { Nectandra } \\
\text { lanceolata Nees \& } \\
\text { Mart. }\end{array}$ & Canela-amarela & $\mathrm{ZOO}$ & $\mathrm{I} ; \mathrm{M} ; \mathrm{A}$ \\
\hline & $\begin{array}{c}\text { Nectandra } \\
\text { grandiflora Nees \& } \\
\text { Mart. }\end{array}$ & Canela-fedida & $\mathrm{ZOO}$ & $\mathrm{I} ; \mathrm{M} ; \mathrm{A}$ \\
\hline & $\begin{array}{c}\text { Cryptocarya } \\
\text { aschersoniana Mez. }\end{array}$ & Canela-batalha & $\mathrm{ZOO}$ & $\mathrm{I} ; \mathrm{M} ; \mathrm{A}$ \\
\hline & $\begin{array}{l}\text { Ocotea odorifera } \\
\text { (Vell.) Rohwer }\end{array}$ & Sassafrás & $\mathrm{ZOO}$ & $\mathrm{M} ; \mathrm{A}$ \\
\hline & $\begin{array}{c}\text { Ocotea puberula } \\
\text { (Rich.) Nees }\end{array}$ & Canela-guaicá & $\mathrm{ZOO}$ & I;M;A \\
\hline & Indeterminada 1 & Canela & & \\
\hline LORANTHACEAE & Loranthaceae 1 & & $\mathrm{ZOO}$ & \\
\hline MELIACEAE & Cedrela fissilis Vell. & Cedro & ANE & I;M;A \\
\hline MONIMIACEAE & $\begin{array}{c}\text { Hennecartia } \\
\text { omphalandra Poiss. }\end{array}$ & & $\mathrm{ZOO}$ & \\
\hline MYRSINACEAE & $\begin{array}{c}\text { Myrsine umbellata } \\
\text { Mart. }\end{array}$ & Capororocão & $\mathrm{ZOO}$ & M \\
\hline
\end{tabular}




\begin{tabular}{|c|c|c|c|c|}
\hline FAMÍLIA & ESPÉCIE & NOME VULGAR & DISPERSÃO & $\begin{array}{c}\text { ESTÁGIO } \\
\text { SUCESSIONAL }\end{array}$ \\
\hline \multirow[t]{15}{*}{ MYRTACEAE } & $\begin{array}{l}\text { Calyptranthes } \\
\text { concinna DC. }\end{array}$ & Guamirim-facho & $\mathrm{ZOO}$ & A \\
\hline & Calyptranthes sp & & $\mathrm{ZOO}$ & $\mathrm{M}$ \\
\hline & $\begin{array}{c}\text { Campomanesia } \\
\text { guaviroba (DC.) } \\
\text { Kiaersk. } \\
\end{array}$ & Guabiroba & $\mathrm{ZOO}$ & $\mathrm{I} ; \mathrm{M} ; \mathrm{A}$ \\
\hline & $\begin{array}{c}\text { Eugenia } \\
\text { neoverrucosa } \\
\text { Sobral }\end{array}$ & & $\mathrm{ZOO}$ & \\
\hline & $\begin{array}{c}\text { Eugenia pluriflora } \\
\text { DC. }\end{array}$ & Pitanga-verde & $\mathrm{ZOO}$ & \\
\hline & Eugenia uniflora L. & Pitangueira & $\mathrm{ZOO}$ & I;M;A \\
\hline & $\begin{array}{l}\text { Curitiba prismatica. } \\
\text { (D.Legr.)Salywon } \\
\text { \& Landrum }\end{array}$ & Murta, Cambuí & $\mathrm{ZOO}$ & $\mathrm{I} ; \mathrm{M} ; \mathrm{A}$ \\
\hline & $\begin{array}{l}\text { Myrcia retorta } \\
\text { Cambess. }\end{array}$ & $\begin{array}{l}\text { Guamirim- } \\
\text { vermelho }\end{array}$ & $\mathrm{ZOO}$ & \\
\hline & $\begin{array}{c}\text { Myrcia hatschbachii } \\
\text { D.Legr. }\end{array}$ & caingá & $\mathrm{ZOO}$ & M \\
\hline & $\begin{array}{c}\text { Myrcia splendens } \\
\text { (Sw.) DC. }\end{array}$ & Guamirim-chorão & $\mathrm{ZOO}$ & $\mathrm{I} ; \mathrm{M} ; \mathrm{A}$ \\
\hline & $\begin{array}{c}\text { Myrceugenia } \\
\text { myrcioides } \\
\text { (Cambess.) O. } \\
\text { Berg. } \\
\end{array}$ & Guamirim & $\mathrm{ZOO}$ & \\
\hline & Myrtaceae 1 & & $\mathrm{ZOO}$ & \\
\hline & Myrtaceae 2 & & $\mathrm{ZOO}$ & \\
\hline & Myrtaceae 3 & & $\mathrm{ZOO}$ & \\
\hline & Myrtaceae 4 & & $\mathrm{ZOO}$ & \\
\hline ROSACEAE & $\begin{array}{c}\text { Prunus brasiliensis } \\
\text { (Cham. \& } \\
\text { Schltdl.) D.Dietr. }\end{array}$ & Pessegueiro-bravo & $\mathrm{ZOO}$ & $\mathrm{M} ; \mathrm{A}$ \\
\hline \multirow[t]{3}{*}{ RUBIACEAE } & $\begin{array}{l}\text { Coussarea contracta } \\
\text { (Walp.)Benth. \& } \\
\text { Hook.f. ex Muell. } \\
\text { Arg. }\end{array}$ & Pimenteira & $\mathrm{ZOO}$ & $\mathrm{A}$ \\
\hline & $\begin{array}{c}\text { Psychotria } \\
\text { vellosiana Benth. }\end{array}$ & Grandiúva & $\mathrm{ZOO}$ & \\
\hline & Psychotria sp & Grandiúva & $\mathrm{ZOO}$ & M;A \\
\hline
\end{tabular}


(conclusão)

\begin{tabular}{c|c|c|c|c}
\hline \multirow{2}{*}{ FAMÍlIA } & ESPÉCIE & NOME VULGAR & DISPERSÃO & $\begin{array}{c}\text { ESTÁGIO } \\
\text { SUCESSIONAL }\end{array}$ \\
\hline \multirow{2}{*}{ SALICACEAE } & $\begin{array}{c}\text { Casearia decandra } \\
\text { Jacq. }\end{array}$ & Cambroé & ZOO & I;M;A \\
\hline & $\begin{array}{c}\text { Casearia lasiophylla } \\
\text { Eichler }\end{array}$ & Guaçatunga graúda & ZOO & I;M;A \\
\cline { 2 - 5 } & $\begin{array}{c}\text { Casearia obliqua } \\
\text { Spreng. }\end{array}$ & Guaçatunga & ZOO & I;M;A \\
\cline { 2 - 5 } & $\begin{array}{c}\text { Casearia sylvestris } \\
\text { Sw. }\end{array}$ & Café-de-bugre & ZOO & I;M;A \\
\hline SAPINDACEAE & $\begin{array}{c}\text { Matayba } \\
\text { elaeagnoides Radlk. }\end{array}$ & Miguel-pintado & ZOO & I;M;A \\
\hline & Sapindaceae 1 & & & \\
\hline
\end{tabular}

Nota: $\mathrm{ANE}$ = anemocórico; $\mathrm{AUT}$ = autocórico; $\mathrm{ZOO}$ = zoocórico; $\mathrm{I}$ = inicial; $\mathrm{M}$ = médio; $\mathrm{A}$ = avançado.

As famílias que tiveram o maior número de espécies, evidenciando assim maior riqueza específica, foram: Myrtaceae (13 espécies, 58 indivíduos; 30,9\% dos táxons), Lauraceae (6 espécies, 11 indivíduos, 14,3\% dos táxons), Salicaceae (5 espécies, 18 indivíduos, 11,9\% dos táxons). Essas famílias são consideradas características da vegetação de faxinais em florestas com araucária (ALMEIDA et al., 2008; ALBUQUERQUE, 2009) e de ervais nativos (OCCHIONI; HATSCHBACH, 1972).

A espécie mais frequente foi pitanga-verde (Eugenia pluriflora), seguida por caingá (Myrcia hatschbachii) e por pimenteira (Cinnamodendron dinisii). As espécies que apresentaram maior Índice de Valor de Importância (IVI) (Tabela 2), pela sua densidade, dominância e frequência, foram Eugenia pluriflora $(33,8)$, Cinnamodendron dinisii $(15,7)$, Myrcia hatschbachii $(10,6)$ e Casearia inaequilatera $(10,5)$.

Tabela 2 - Relação das espécies arbóreas com os 20 maiores Índices de Valor de Importância (IVI) e respectivos Índice de Valor de Cobertura (IVC), frequência Relativa (FR) e Densidade Relativa (DR) ocorrentes na área do Faxinal Sete Saltos de Baixo, Ponta Grossa, PR

(continua)

\begin{tabular}{c|c|c|c|c}
\hline Espécies & IVI & IVC & FR & DR \\
\hline Eugenia pluriflora & 33,75 & 30,47 & 16,47 & 3,28 \\
\hline Cinnamodendron dinisii & 15,66 & 10,74 & 5,29 & 4,92 \\
\hline Myrcia hatschbachii & 10,67 & 7,39 & 5,88 & 3,28 \\
\hline Casearia obliqua & 10,52 & 5,60 & 4,12 & 4,92 \\
\hline Cedrela fissilis & 10,00 & 8,36 & 0,59 & 3,28 \\
\hline
\end{tabular}


(conclusão)

\begin{tabular}{c|c|c|c|c}
\hline Espécies & IVI & IVC & FR & DR \\
\hline Myrtaceae 3 & 9,81 & 6,53 & 2,94 & 3,28 \\
\hline Ocotea odorifera & 9,59 & 6,31 & 1,76 & 3,28 \\
\hline Casearia sylvestris & 8,89 & 3,97 & 2,94 & 4,92 \\
\hline Curitiba prismatica & 7,32 & 2,40 & 1,76 & 4,92 \\
\hline Matayba elaeagnoides & 6,91 & 3,63 & 2,35 & 3,28 \\
\hline Hennecartia omphalandra & 6,88 & 5,24 & 0,59 & 1,64 \\
\hline Myrsine umbellata & 6,40 & 4,76 & 2,94 & 1,64 \\
\hline Jacaranda macrantha & 5,55 & 3,91 & 1,18 & 1,64 \\
\hline Psychotria sp & 4,88 & 1,60 & 1,18 & 3,28 \\
\hline Loranthaceae 1 & 4,85 & 3,21 & 1,18 & 1,64 \\
\hline Prunus brasiliensis & 4,66 & 1,38 & 1,18 & 3,28 \\
\hline Sapindaceae 1 & 4,56 & 2,92 & 1,18 & 1,64 \\
\hline Nectandra grandiflora & 4,55 & 1,27 & 1,18 & 3,28 \\
\hline Casearia lasiophylla & 4,23 & 2,60 & 2,35 & 1,64 \\
\hline Lonchocarpus muehlbergianus & 3,47 & 1,83 & 1,18 & 1,64 \\
\hline
\end{tabular}

O índice de diversidade de Shannon $\left(\mathrm{H}^{\prime}\right)$ para toda a área analisada foi de 2,92, com uniformidade de Pielou (J) de 0,78. Nakajima et al. (1996), em uma área considerada bem conservada de Telêmaco Borba, encontraram uma diversidade de 3,61. Moro et al. (2001), analisando a floresta ripária impactada do rio Cará Cará, em Ponta Grossa, encontraram um índice $\mathrm{H}^{\prime}$ de 2,97. Índices de diversidade permitem estabelecer diferenças relacionadas com a riqueza e a uniformidade da distribuição das abundâncias relativas dos indivíduos dentro de cada espécie. Avaliam, em geral, a organização do ecossistema, onde etapas maduras, compostas por comunidades mais organizadas, apresentam maior diversidade que etapas mais primitivas, constituídas por comunidades pioneiras. A uniformidade avalia o nível de agregação da distribuição e varia de 0 , numa distribuição totalmente agregada, a 1 numa distribuição totalmente homogênea. Pode-se dizer que 
o criadouro comunitário deste Faxinal apresenta uma diversidade compatível com uma área manejada (impactada), com valores intermediários à diversidade levantada em faxinais por Almeida et al. (2008), de 3,26, e por Albuquerque (2009), de 2,59.

Quanto ao tipo de dispersão, predomina largamente o tipo zoocórico, ou seja, sementes dispersas por animais (aves, morcegos, pequenos roedores), com $89,8 \%$ de frequência; 5,1\% são anemocóricas (dispersão aérea) e 5,1\% pertencem a espécies autocóricas (que dispersam sementes por gravidade ou apresentam mecanismos de autodispersão, como a deiscência explosiva). Almeida et al (2008) encontraram uma proporção maior de anemocóricas e autocóricas (17,6 e 15,4\% respectivamente) num faxinal em General Carneiro, mas citam que a dispersão zoocórica é característica de ambientes em estágio sucessional mais avançado, onde as redes tróficas estão mais bem estabelecidas. $\mathrm{O}$ manejo e a recuperação das florestas alteradas dependem da eficiência destes processos de dispersão e do estabelecimento de espécies de diferentes estágios sucessionais, sendo a manutenção da fauna, portanto, bastante importante na manutenção da regeneração natural durante a dinâmica de sucessão da floresta analisada.

Com relação ao estágio sucessional típico de cada espécie, as indiferentes são as mais frequentes (43,6\%), ou seja, aquelas características dos estágios tanto inicial e médio quanto avançado. Comparando os dados do Faxinal Sete Saltos de Baixo com as listas de Castella e Britez (2004) para a região, o criadouro comunitário pode-se comparar a florestas em estágio médio de regeneração (capoeirão), com um estrato arbóreo médio de nove metros de altura, tendo como espécies características: Campomanesia guaviroba, Cinnamodendron dinisii, Casearia lasiophylla, Casearia sylvestris, Cedrela fissilis, Eugenia pluriflora, Matayba elaeagnoides, Myrcia hatschbachii, Myrcia splendens, Nectandra grandiflora, Nectandra lanceolata, Ocotea puberula e Ocotea odorifera.

Embora espécies de maior índice de Importância, como Cinnamodendron dinisii, Matayba elaeagnoides e Nectandra grandiflora enquadrem a vegetação do criadouro na comunidade 2 da classificação de Leite (1994), espécies tradicionais da floresta com araucária não estão presentes. A ausência de Araucaria angustifolia e Ilex paraguariensis demonstra que a vegetação, neste local, encontra-se impactada e bastante descaracterizada. Para Albuquerque (2009), a falta de tais espécies num faxinal "deve-se principalmente ao sistema de manejo da floresta com a presença de animais em seu interior. Tal fator altera a dinâmica da vegetação, dificultando a regeneração e o crescimento da floresta" (ALBUQUERQUE, 2009, p.50). Por outro lado, podem ser observadas espécies madeireiras de maior valor econômico como canela-guaicá (Ocotea puberula), canela-sassafrás (Ocotea odorifera) e cedro (Cedrela fissilis).

De acordo com o sistema de classificação proposto por Sanquetta e Mattei (2006), a área em estudo se enquadra na tipologia de Floresta Antropizada por Sistemas Agrosilvopastoris, provocado pelo "raleamento ou corte parcial do dossel ou do subdossel da floresta" (SANQUETTA; MATTEI, 2006, p.23). Ou seja, uma floresta que dificilmente se enquadraria na definição da resolução CONAMA 002/94 devido ao seu manejo, com retirada seletiva de madeira, exploração de erva-mate e dificuldades de regeneração pelo pastoreio no sub-bosque. 


\section{CONCLUSÕES}

O levantamento fitossociológico no Faxinal Sete Saltos de Baixo, município de Ponta Grossa, PR, apontou uma Floresta Ombrófila Mista Montana que se enquadra na tipologia de Floresta Antropizada por Sistemas Agrosilvopastoris. A ausência de espécies típicas em faxinais, como Araucaria angustifolia e Ilex paraguariensis, deve-se à retirada seletiva de madeira no passado e à forma de manejo, com a presença de animais que altera a dinâmica da vegetação.

No entanto, a altura de dossel e a presença de espécies indicadoras de ambientes em sucessão intermediária, aliada à expressiva presença de espécies zoocóricas, aponta para uma floresta em estágio sucessional médio ou avançado pelo corte seletivo e retirada das árvores de maior porte que formavam o dossel florestal primário.

Em relação à categoria ARESUR, no que tange à vegetação, o Faxinal Sete Saltos de Baixo não estaria apto a recebê-la ainda, pois se encontra em um estado de degradação ambiental, provocada pelas atividades de produção, em contraposição à conservação da Floresta Ombrófila Mista ainda existente. No entanto, com a ampliação do ICMS Ecológico, sua remuneração dos serviços ambientais poderia contribuir para a busca da sustentabilidade, garantindo ao Sistema Faxinal a continuidade dos fatores sociais, culturais, econômicos e ambientais.

\section{REFERÊNCIAS}

ALBUQUERQUE, J. M. de. Florística, estrutura e aspectos físicos de Floresta Ombrófila Mista em Sistema Faxinal no município de Rebouças, Paraná. Irati, 2009. 104f. Dissertação (Mestrado em Engenharia Florestal) - UNICENTRO, Irati - PR.

ALMEIDA, S. R.; WATZLAWICK, Luciano F.; MYSZKA, Eloi; VALERIO, Álvaro F. Florística e síndromes de dispersão de um remanescente de Floresta Ombrófila Mista em sistema faxinal. Ambiência, v.4, n.2, p.289-297, Maio/Ago. 2008.

APG III. An update of the Angiosperm Phylogeny Group classification for the orders and families of flowering plants: APG III. Botanical Journal of the Linnean Society, v. 161, n.2, p. 105-121, 2009.

CASTELLA, P. R.; BRITEZ, R. M. (Orgs.). A Floresta com Araucária no Paraná: conservação e diagnóstico dos remanescentes florestais. Brasília: MMA, 2004.

CHANG, Man Yu. Sistema faxinal: uma forma de organização camponesa em desagregação no centrosul do Paraná. Londrina, IAPAR, 1988 (Boletim Técnico, 22).

CONAMA. Resolução n. 002/94. Define vegetação primária e secundária nos estágios inicial, médio e avançado de regeneração da Mata Atlântica no Estado do Paraná (regulamentação do artigo $6^{\circ}$ do Decreto 750/93). Convalidada pela Res. CONAMA n. 388, de 23 de fevereiro de 2007.

CORREAA, P. M. Dicionário das plantas úteis do Brasil e das exóticas cultivadas. Rio de Janeiro: Ministério da Agricultura/Serviço de informação agrícola, v. 1, 1926; v. 2, 1931, v. 3, 1952; v. 4, 1969; v. 5, 1974; v. 6, 1975.

FERREIRA, E. S.; CARVALHO, S. M. Evolução do uso da terra na bacia hidrográfica do rio Sete Saltos, Ponta Grossa (PR) 1980-2006. In: SEMANA DE GEOGRAFIA, 12. JORNADA CIENTIFICA DE GEOGRAFIA DA UEPG, 8. 2006, Ponta Grossa. Resumos (CD-ROM). 
FIDALGO, O.; BONONI, V. L. R. (Coord.). Técnicas de coleta, preservação e herborização de material botânico. São Paulo, Instituto de Botânica. Série Documentos. 1989.

GUBERT FILHO, F. A. O Faxinal: estudo preliminar. Revista do direito Agrário e Meio Ambiente, Curitiba, v. 2, p. 32-40, ago. 1987.

IAP. Instituto Ambiental do Paraná. ICMS ecológico em perguntas e respostas: instruções básicas para unidades de conservação. SEMA, IAP. Curitiba, 1998.

LEITE, P. F. As diferentes unidades fitoecológicas da Região Sul do Brasil: proposta de classificação. 1994. 160f. Dissertação (Mestrado em Engenharia Florestal) - Setor de Ciências Agrárias, Universidade Federal do Paraná, Curitiba, 1994.

LORENZI, H. Árvores brasileiras. Nova Odessa: Plantarum, v.1, 1992; v.2, 1998.

MORO, R. S; SCHMITT, J; DIEDRICHS, L. A. Estrutura de um fragmento da mata ciliar do Rio Cará-Cará, Ponta Grossa, PR. Publicatio UEPG, Ciências Biológicas e da Saúde, Ponta Grossa, v. 7, n.1, p. 19-38, 2001.

LÖWEN SAHR, C. L.; CUNHA, L. A. G. O significado social e ecológico dos faxinais: reflexões acerca de uma política agrária sustentável para a região da mata com araucária no Paraná. Emancipação, v.5, n. 1, p. 89-104, 2005.

MUELLER-DUMBOIS, D.; ELLENBERG, H. Aims and methods vegetation ecology. New York: John Wiley \& Sons, 1974.

NAKAJIMA, J. N. et al. Composição florística e fitossociológica do componente arbóreo das florestas ciliares da bacia do Rio Tibagi, Paraná. 6. Fazenda Monte Alegre, município de Telêmaco Borba, Paraná. Arquivos de Biologia e Tecnologia, v.39, n.4, p.933-948, dez. 1996.

OCCHIONI, P.; HATSCHBACH, G. A vegetação arbórea dos ervais do Paraná. Leandra, v.2, n.3, p.5-59, dez. 1972.

PARANÁ. Decreto Estadual n. ${ }^{\circ} 3466$ de 14 de agosto de 1997. Dispõe as ARESUR - Áreas Especiais de Uso Regulamentado - que abrange porções territoriais do Estado, caracterizada pela existência do modo de produção denominado Sistema de Faxinal. Diário Oficial do Paraná, Curitiba. Disponível em <http:// www.pr.gov.br>. Acesso em: 30 maio 2011.

PIJL, L. V. D. Principles of dispersal in higher plants. 2. ed. Berlin: Springer Verlag. 1982.

SANQUETTA, C. R.; MATTEI, E. Perspectivas de recuperação e manejo sustentável das florestas de Araucária. Curitiba: Multi-Graphic, 2006.

SEPLAN - PR. Faxinais: um modelo de desenvolvimento auto-sustentado. Curitiba: SEPL, 1994.

SHEPHERD, G. J. FITOPAC: manual do usuário. Campinas, UNICAMP, 1994.

STRUMINSKI, Edson; STRACHULSKI, Juliano. Florestas em faxinais: abordagem fitogeográfica e revisão de conceitos. In: SIMPÓSIO DE PESQUISADORES EM FAXINAIS, 1., Ponta Grossa, 2011. Anais... v.1. p.199-224.

VELOSO, H. P.; RANGEL FILHO, A. L. R.; LIMA, J. C. A. Classificação da vegetação brasileira, adaptada a um sistema universal. IBGE: Rio de Janeiro, 1991.

Recebido em 12/02/2012

Aceito para publicação em 29/03/2012 